\title{
Solvent Extraction of Ni(II) from Sulfate Solutions with LIX 84I: Flow-Sheet for the Separation of $\mathrm{Cu}(\mathrm{II}), \mathrm{Ni}(\mathrm{II})$ and $\mathrm{Zn}(\mathrm{II})$
}

\author{
B. Ramachandra REDDY ${ }^{\dagger}$ and D. Neela PRIYA
}

\author{
Inorganic Chemistry Division, Indian Institute of Chemical Technology (CSIR), Hyderabad 500 007, India
}

\begin{abstract}
This paper reports on solvent-extraction studies of $\mathrm{Ni}(\mathrm{II})$ from sulfate solutions with LIX 84I (2-hydroxy-5nonylacetophenoneoxime) as the extractant. The extraction of metal depends on the equilibrium $\mathrm{pH}$ of the aqueous phase and the extractant concentration. The transfer of metal follows a cation exchange-type mechanism: $\mathrm{Ni}^{2+}+2 \mathrm{HA} \rightarrow \mathrm{NiA}_{2}$ $+2 \mathrm{H}^{+}$. Extraction varies with the nature of the diluents. Temperature has no effect on the extraction of metal. The extraction behavior of associated metals clearly demonstrates the application of LIX 84I as the extractant for the separation of $\mathrm{Cu}(\mathrm{II}), \mathrm{Ni}(\mathrm{II})$ and $\mathrm{Zn}(\mathrm{II})$. Based on the results, a flow sheet of the process was developed.
\end{abstract}

(Received May 20, 2004; Accepted August 19, 2004)

\section{Introduction}

Nickel is primarily used as an alloying metal. The other uses of nickel are in electroplating and batteries, and as catalysts. Sulfidic, oxidic nickel ores and various nickel bearing secondary materials, such as super alloy scrap, spent batteries and catalysts, dust etc., are potential sources for nickel production.

Nickel-bearing ores/concentrates/other raw materials are treated either by hydrometallurgical or pyrometallurgical routes. In general, untreated or pretreated materials are leached in an ammoniacal or acidic medium. Sulfuric acid, hydrochloric acid or their mixtures are used for the dissolution/leaching of secondaries, such as super-alloy scrap. Thus-obtained leach solutions chiefly contain nickel and cobalt, along with other impurities, such as iron, copper, chromium, aluminum and silica. From such solutions, iron, chromium, aluminum, silica are removed by lime precipitation. Liquid-liquid extraction has been applied to many solutions to obtain either metals or salts in highly pure form. The most widely used extractants are phosphoric acid based alkyl phosphorous reagents D2EHPA, PC 88A, Cyanex 272, or their equivalents. These alkyl phosphorous acid extractants, although they extract both cobalt and nickel, have selectively for cobalt over nickel. ${ }^{1-6}$ In our earlier studies, LIX 84I was used for the recovery of $\mathrm{Ni}$ (II) from ammoniacal sulfate liquor containing Ni: $20.5 \mathrm{~g} \mathrm{~L}^{-1}$, Co: $0.2 \mathrm{~g}$ $\mathrm{L}^{-1}$ and $\left(\mathrm{NH}_{4}\right) \mathrm{SO}_{4}$ : $23.6 \mathrm{~g} \mathrm{~L}^{-1} .^{7}$ Literature reveals that this extractant was extensively used for copper extraction..$^{8-12}$ Price and $\operatorname{Reid}^{13}$ described the separation of nickel from cobalt, both present as amines, using modified LIX 84 I.

In this paper, we report on the solvent extraction of nickel(II) from sulfate solutions using LIX 84I as the extractant. The parameters studied are: the effect of the $\mathrm{pH}$, the extractant concentration, diluents, loading capacity of the extractant, regeneration and recycling, stripping, extraction behavior of associated metals and finally the development of a flow-sheet

$\dagger$ To whom correspondence should be addressed.

E-mail: brcreddy_iict@yahoo.com for the separation and recovery of copper(II), nickel(II) and zinc(II) from a typical synthetic sulfate solution using LIX 84I.

\section{Experimental}

\section{Apparatus and reagents}

A Perkin Elmer Model A300 atomic absorption spectrometer and a digital Digisun (DI 707 Model) $\mathrm{pH}$ meter with a combined glass electrode were used. The IR spectrum of the metal complex was recorded using a FTIR-Nicolet (USA)-740spectrophotometer.

A stock solution of a $0.1 \mathrm{~mol} \mathrm{dm}{ }^{-3}$ nickel(II) solution was prepared by dissolving the requisite quantity of Analar $\mathrm{NiSO}_{4}$ in distilled water. The nickel solution was standardized against a $0.05 \mathrm{~mol} \mathrm{dm}^{-3}$ EDTA solution ${ }^{14}$ using a murexide indicator. Working standard solutions were prepared by suitable dilution of this stock solution. LIX 84I is a proprietary product of $\mathrm{M} / \mathrm{s}$. Cognis is a 2-hydroxy-5-t-nonylacetophenonoxime having a molecular weight of $\sim 263^{13}$ was used as such. Distilled kerosene (bp. $433-473 \mathrm{~K}$ ) was used as the diluent. All other chemicals and reagents used were of Analar grade.

\section{General extraction procedure}

A suitable aliquot $(10 \mathrm{ml})$ of a solution containing metal ion was equilibrated with an equal volume of LIX 84 I for $20 \mathrm{~min}$ in a separating funnel. Initial experiments on the effect of time on metal extraction indicated that $15 \mathrm{~min}$ is sufficient to reach an equilibrium reaction. Adding dilute $\mathrm{H}_{2} \mathrm{SO}_{4}$ or $\mathrm{NaOH}$ adjusted the equilibrium $\mathrm{pH}$ of the aqueous solution to the desired value. After phase disengagement, the aqueous phase was separated and the metal concentrations were analyzed by AAS. The distribution ratio, $(D)$ was calculated as the concentration of the metal present in the organic phase to that part in the aqueous phase at equilibrium. As and when required, the metal concentration in the organic phase was determined after filtration through a 1PS paper and stripping a suitable aliquot with $1 \mathrm{~mol} \mathrm{dm}^{-3} \mathrm{HCl}$, followed by analysis. All of the experiments were carried out at room temperature $(303 \pm 1 \mathrm{~K})$. 


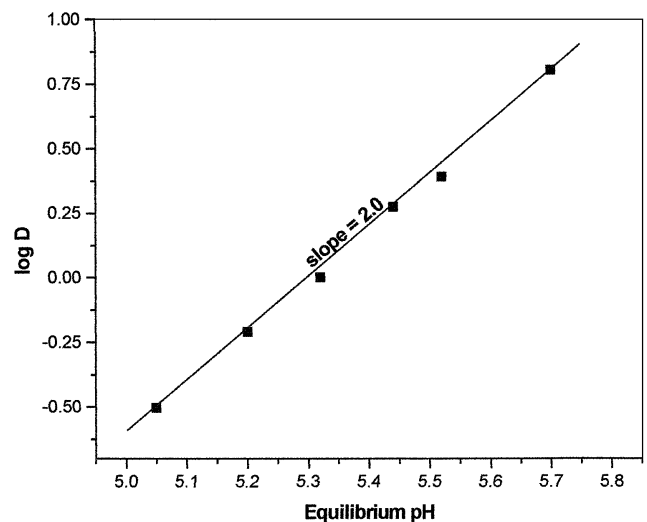

Fig. 1 Plot of the equilibrium $\mathrm{pH}$ vs $\log D$. Extraction conditions: $\mathrm{Ni}(\mathrm{II}), 0.0025 \mathrm{~mol} \mathrm{dm}^{-3}$; LIX 84I, $0.01 \mathrm{~mol} \mathrm{dm}^{-3}$.

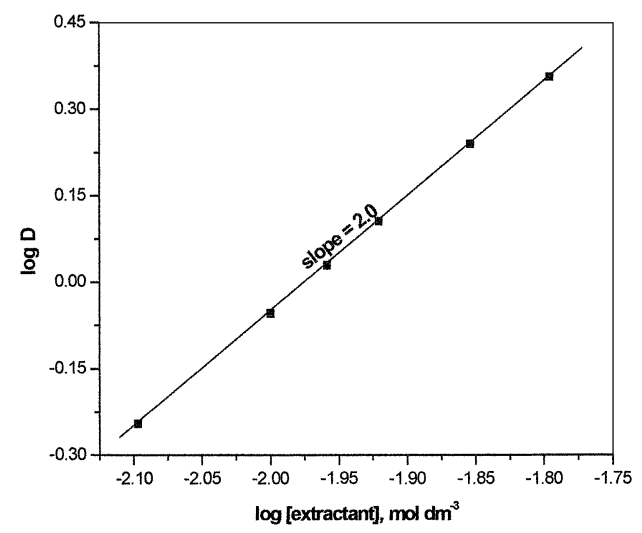

Fig. 2 Plot of $\log \left[\right.$ extractant], mol $\mathrm{dm}^{-3} v s . \log D$. Extraction conditions: $\mathrm{Ni}(\mathrm{II}), 0.005 \mathrm{~mol} \mathrm{dm}^{-3}$; equilibrium $\mathrm{pH}, 7.50$.

\section{Results and Discussion}

\section{Extraction mechanism and species}

The extraction equilibrium of nickel(II) from sulfate solutions with LIX 84I as an extractant may be represented as:

$$
\mathrm{Ni}^{2+}{ }_{(\mathrm{aq})}+2 \mathrm{HA}_{(\text {org })} \stackrel{K_{\mathrm{ex}}}{\longrightarrow} \mathrm{NiA}_{2(\text { org })}+2 \mathrm{H}^{+}(\text {aq) },
$$

where $K_{\text {ex }}$ denotes the equilibrium constant.

$$
\begin{aligned}
& K_{\text {ex }}=\frac{\left[\mathrm{NiA}_{2}\right]\left[\mathrm{H}^{+}\right]^{2}}{\left[\mathrm{Ni}^{2+}\right][(\mathrm{HA})]^{2}}, \\
& K_{\text {ex }}=\frac{D\left[\mathrm{H}^{+}\right]^{2}}{[(\mathrm{HA})]^{2}}, \\
& \text { where } D=\frac{\left[\mathrm{NiA}_{2}\right]}{\left[\mathrm{Ni}^{2+}\right]} .
\end{aligned}
$$

Taking the logarithm of Eq. (3) and rearranging,

$$
\log D=\log K_{\mathrm{ex}}+2 \log [\mathrm{HA}]+2 \mathrm{pH} \text {. }
$$

Analyzing the experimental data of distribution ratio $(D)$ as a function of the equilibrium $\mathrm{pH}$ and the extractant concentration at constant value of other parameters allows an estimation of the

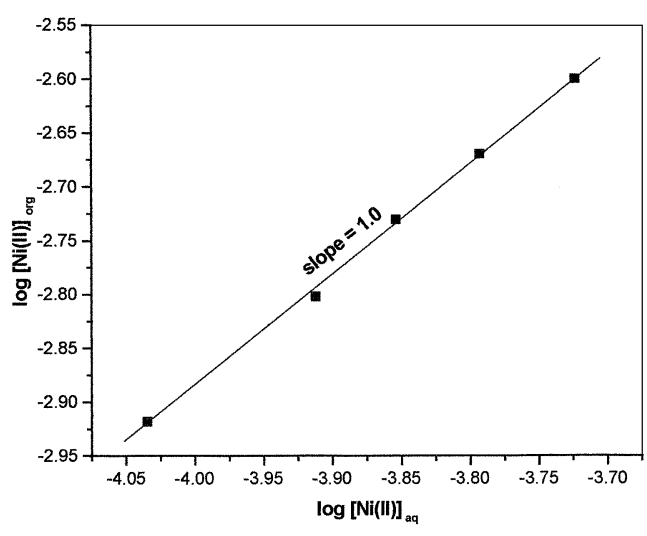

Fig. 3 Plot of $\log [\mathrm{Ni}(\mathrm{II})]_{\text {aq }} v s . \log [\mathrm{Ni}(\mathrm{II})]_{\text {org }}$. Extraction conditions: LIX 84I, $0.01 \mathrm{~mol} \mathrm{dm}^{-3}$; equilibrium $\mathrm{pH}, 7.50$.

number of extractant molecules associated with the extracted metal complex.

The extraction of nickel $\left(0.0025 \mathrm{~mol} \mathrm{dm}^{-3}\right)$ with LIX 84I $(0.01$ mol dm${ }^{-3}$ and $0.005 \mathrm{~mol} \mathrm{dm}^{-3}$ ) as a function of the $\mathrm{pH}$ showed an increase in the percentage extraction with an increase in the equilibrium $\mathrm{pH}$. Further, a plot of $\log D$ vs. equilibrium $\mathrm{pH}$ (Fig. 1) gave a straight line with a slope of 2.0, indicating the exchange of two moles of $\mathrm{H}^{+}$for every mole of metal ion during the extraction process.

The effect of the LIX 84I concentration $(0.005$ to $0.05 \mathrm{~mol}$ $\left.\mathrm{dm}^{-3}\right)$ on the extraction of $\mathrm{Ni}$ (II) $\left(0.005 \mathrm{~mol} \mathrm{dm}^{-3}\right)$ was investigated. It was observed that the extraction of nickel increased with an increase in the extractant concentration. A plot of $\log D v s . \log [\mathrm{HA}]$ (Fig. 2) gave a straight line with a slope of 2 , indicating that two moles of the extractant $(\mathrm{HA}=$ LIX 84I) were involved with the extracted complex.

The effect of nickel concentration $\left(0.001-0.003 \mathrm{~mol} \mathrm{dm}^{-3}\right)$ on the extraction was investigated using LIX $84 \mathrm{I}\left(0.01 \mathrm{~mol} \mathrm{dm}^{-3}\right)$ at an equilibrium $\mathrm{pH}$ of 7.50. The extraction of nickel(II) was found to be independent of the metal ion concentration in the aqueous phase. A log-log plot (Fig. 3) of the equilibrium organic phase metal concentration against the aqueous phase metal concentration is linear with a slope of 1.0, indicating the extraction of mononuclear species into the organic phase. The species extracted into the organic phase appears to be $\mathrm{NiA}_{2}$.

\section{Effect of salts}

The effect of salts, such as $\mathrm{NaCl}, \mathrm{Na}_{2} \mathrm{SO}_{4}, \mathrm{NaNO}_{3}$ and $\mathrm{NaSCN}$, was studied in the concentration range $0.2-2.0 \mathrm{~mol}$ $\mathrm{dm}^{-3}$ on the extraction behavior of $0.001 \mathrm{~mol} \mathrm{dm}^{-3} \mathrm{Ni}$ (II) with $0.01 \mathrm{~mol} \mathrm{dm}^{-3}$ LIX 84I. It was observed that there was a decrease in the percentage extraction of $\mathrm{Ni}$ (II) from $100-88.6 \%$ along with an increase in the salt concentration, when $\mathrm{NaNO}_{3}$ was used as the salt. With other salts, the decrease in the percentage of extraction was marginal (100-95\%). At a given concentration of metal and extractant, the percentage extraction followed in decreasing order as $\mathrm{NaNO}_{3}>\mathrm{Na}_{2} \mathrm{SO}_{4}>\mathrm{NaCl}>$ NaSCN.

\section{Effect of diluents and temperature}

The extraction of $\mathrm{Ni}(\mathrm{II})\left(0.001 \mathrm{~mol} \mathrm{dm}^{-3}\right)$ using LIX 84I (0.01 mol $\mathrm{dm}^{-3}$ ) at an equilibrium $\mathrm{pH}$ of 7.5 in various diluents was investigated. The results demonstrate that the extraction of $\mathrm{Ni}(\mathrm{II})$ varies with the nature of the diluent, and decreases in the following order: xylene $(D=1.15)<$ chloroform $(D=3.61)<$ toluene $(D=7.33)<$ carbon tetrachloride $(D=10.32)<$ benzene 


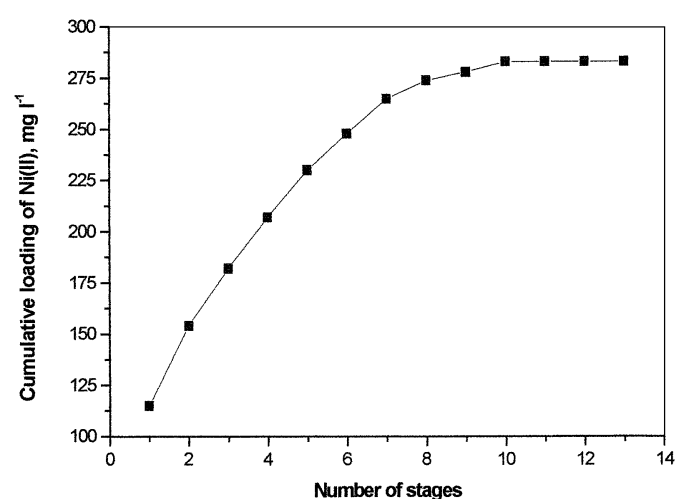

Fig. 4 Plot of the stage number $v s$. loading of organic phase by $\mathrm{Ni}(\mathrm{II})$. Loading conditions: $\mathrm{Ni}(\mathrm{II}), 0.005 \mathrm{~mol} \mathrm{dm}^{-3}$; LIX 84I, 0.01 mol dm ${ }^{-3}$; equilibrium $\mathrm{pH}, 7.50$.

$(D=17.3)<$ cyclohexane $(D=32)<n$-hexane $(D=47.8)<$ kerosene $(D=233.3)$. In the present study, kerosene was used, considering the point that it is the cheapest commercially available diluent. The variation of the temperature in the range of $303-333 \mathrm{~K}\left( \pm 1^{\circ}\right)$ on the extraction of metal from an aqueous solution containing $0.0025 \mathrm{~mol} \mathrm{dm}^{-3} \mathrm{Ni}$ (II) and $0.01 \mathrm{~mol} \mathrm{dm}^{-3}$ LIX 84I at an equilibrium $\mathrm{pH}$ of 7.5 was studied. The results demonstrated that the temperature had no effect on either the percentage extraction or stripping of $\mathrm{Ni}(\mathrm{II})$, and remained constant with an increase in temperature $(D=1.015 \pm 0.002)$.

\section{Loading capacity of the extractant}

An aliquot of $10 \mathrm{ml}$ of $0.01 \mathrm{~mol} \mathrm{dm}^{-3}$ LIX 84I was repeatedly contacted at $303 \pm 1 \mathrm{~K}$ for $15 \mathrm{~min}$ with the same volume of aqueous solutions containing $0.005 \mathrm{~mol} \mathrm{dm}^{-3}$ of $\mathrm{Ni}(\mathrm{II})$. After equilibration, the phases were analyzed for nickel content. The amount of nickel transferred into the organic phase in each contact was calculated based on the difference, and the cumulative concentration of nickel in the organic phase after each stage of contact was determined. A plot of the cumulative [Ni(II) $]_{\text {org }}$ of LIX 84I versus the contact number is shown in Fig. 4. It is clear that nickel existing in the aqueous phase was extracted into the organic phase up to 10th contact, and thereafter remained constant. An analysis of L.O. containing $0.283 \mathrm{~g} \mathrm{~L}^{-1} \mathrm{Ni}(\mathrm{II})$, which corresponds to a loading efficiency of $97 \%$ of the extractant, indicated that the extractant used was in the pure form.

\section{Stripping studies}

The behavior of acids on the stripping of loaded organic containing $0.283 \mathrm{~g} \mathrm{~L}^{-1} \mathrm{Ni}(\mathrm{II})$ was studied using different stripping agents, such as $\mathrm{HCl}, \mathrm{H}_{2} \mathrm{SO}_{4}$ and $\mathrm{HNO}_{3}$, in the concentration range of $0.5-8.0 \mathrm{~mol} \mathrm{dm}^{-3}$. The results show a marginal variation of the stripping efficiency (from $95-99.3 \%$ ) with increasing acid concentration.

\section{Regeneration and recycling capacity of LIX 84}

The recycling capacity of $0.01 \mathrm{~mol} \mathrm{dm}^{-3}$ LIX 84I for the extraction of $\mathrm{Ni}(\mathrm{II})$ (using $0.0025 \mathrm{~mol} \mathrm{dm}^{-3}$ metal and equilibrium $\mathrm{pH}$ 5.32) was carried out by first loading the extractant with $\mathrm{Ni}(\mathrm{II})$, and then stripping with $1 \mathrm{~mol} \mathrm{dm}^{-3} \mathrm{H}_{2} \mathrm{SO}_{4}$ at the unit phase ratio. Single-stage extraction gave L.O. containing $0.055 \mathrm{~g} \mathrm{~L}^{-1} \mathrm{Ni}(\mathrm{II})$, corresponding to an extraction efficiency of $50 \%$ (Fig. 1). The stripped organic phase was washed with distilled water once and then used for extraction.

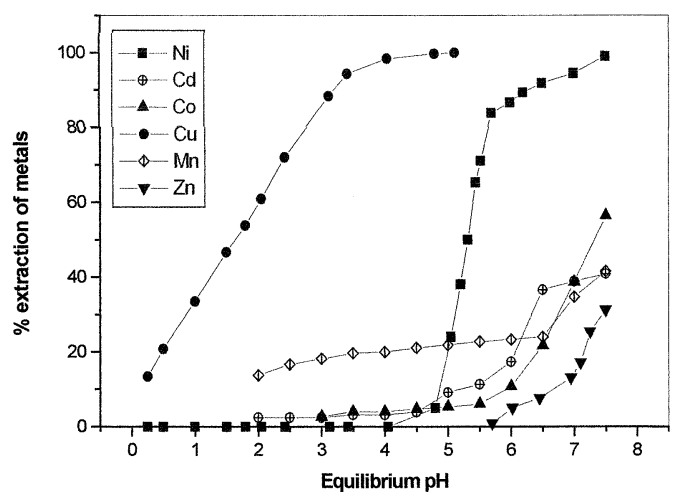

Fig. 5 Extraction behavior of associated metals as a function of the equilibrium $\mathrm{pH}$. Extraction conditions: $\mathrm{Ni}, \mathrm{Cd}, \mathrm{Co}, \mathrm{Cu}, \mathrm{Mn}$, and $\mathrm{Zn}$, $0.0025 \mathrm{~mol} \mathrm{dm}^{-3}$; LIX 84I, $0.1 \mathrm{~mol} \mathrm{dm}^{-3}$.

The results revealed a practically insignificant change in the extraction $(50 \%)$ and stripping efficiency $(100 \%)$ of these extractants up to ten cycles of extraction.

\section{IR studies}

Characterization studies for confirming the Ni-LIX 84I complex in the organic phase were studied by FT-IR. L.O. containing $0.283 \mathrm{~g} \mathrm{~L}^{-1} \mathrm{Ni}(\mathrm{II})$ was used for this study. In the IR spectrum of the complex, the characteristic $\mathrm{N}-\mathrm{OH}$ group of the LIX 84I that is present around $3500 \mathrm{~cm}^{-1}$ (LIX 84I reference sample) is absent in the complex, since the metal appeared to be bonded to nitrogen. Also, the stretching frequency of the band increased from $950 \mathrm{~cm}^{-1}$ to $974.94 \mathrm{~cm}^{-1}$ (which is the characteristic of aryl group), showing a shift in that region, thus confirming bond formation.

\section{Extraction behavior of associated elements}

The extraction behavior of $\mathrm{Ni}(\mathrm{II})$ with other commonly associated metal ions, namely $\mathrm{Cd}, \mathrm{Co}, \mathrm{Cu}, \mathrm{Mn}$ and $\mathrm{Zn}$, of $0.0025 \mathrm{~mol} \mathrm{dm}^{-3}$ concentration was studied with $0.1 \mathrm{~mol} \mathrm{dm}^{-3}$ LIX 84I. Figure 5 gives the extraction curves of these metals with LIX 84I. It was observed that the percent extraction of metals depended mainly on the equilibrium $\mathrm{pH}$ of the aqueous phase. The extraction of $\mathrm{Cu}$ (II) started at $\mathrm{pH}$ values of $<0.2$, and reached quantitative extraction at equilibrium $\mathrm{pH} \sim 4.0$. Under these conditions, the extraction of $\mathrm{Co}$ and $\mathrm{Cd}$ was less than 5 and $\mathrm{Mn} \sim 20 \%$. The extraction of $\mathrm{Ni}$ and $\mathrm{Zn}$ was nil. These results indicate that the extraction of nickel started after equilibrium at $\mathrm{pH} \mathrm{4}$, and reached more than $90 \%$ upon equilibrium at $\mathrm{pH}$ 5.7, which is much below $\mathrm{Zn}$ extraction starting $\mathrm{pH}$. Finally, the results clearly demonstrate the possible separation of $\mathrm{Cu}(\mathrm{II}), \mathrm{Ni}(\mathrm{II})$ and $\mathrm{Zn}(\mathrm{II})$ from their mixtures.

\section{Flow sheet for the separation and recovery of $\mathrm{Cu}, \mathrm{Ni}$ and $\mathrm{Zn}$}

Based on the data for the extraction behavior of $\mathrm{Ni}$ (II) with the associated elements, a flow sheet for the separation of $\mathrm{Ni}$ from $\mathrm{Cu}$ and $\mathrm{Zn}$ has been proposed while taking into account differences in their percentage extraction as a function of the equilibrium $\mathrm{pH}$ of the aqueous phase. For this purpose, a synthetic solution containing $\mathrm{Ni}, \mathrm{Cu}$ and $\mathrm{Zn}\left(\mathrm{Cu}: 0.150 \mathrm{~g} \mathrm{~L}^{-1}\right.$, Ni: $0.140 \mathrm{~g} \mathrm{~L}^{-1}, \mathrm{Zn}: 0.161 \mathrm{~g} \mathrm{~L}^{-1}$ ) was prepared.

The flow-sheet of the process for the recovery of $\mathrm{Cu}, \mathrm{Ni}$ and Zn using $0.5 \mathrm{~mol} \mathrm{dm}^{-3}$ LIX 84I is shown in Fig. 6. The solution was first subjected to copper extraction in a single stage at an equilibrium $\mathrm{pH}$ of 4.0 and an $\mathrm{A}: \mathrm{O}$ ratio of $1: 1$, which gave 


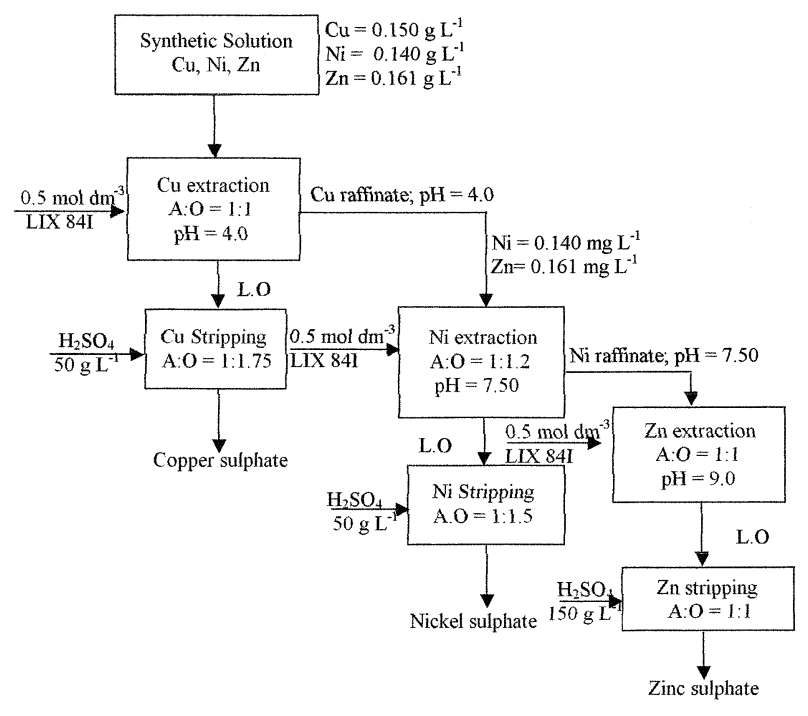

Fig. 6 Flow sheet for the separation of nickel, copper and zinc. Conditions: $\mathrm{Cu}, 0.150 \mathrm{~g} \mathrm{~L}^{-1}$; Ni, $0.140 \mathrm{~g} \mathrm{~L}^{-1}$; Zn, $0.161 \mathrm{~g} \mathrm{~L}^{-1}$; LIX $84 \mathrm{I}, 0.5 \mathrm{~mol} \mathrm{dm}^{-3}$.

99.7\% Cu extraction efficiency. Further, a two-stage countercurrent simulation test for the separation of $\mathrm{Cu}$ at an $\mathrm{A}: \mathrm{O}$ ratio of $1: 1$ gave a copper extraction efficiency of $99.9 \%$. The $\mathrm{Cu}$ raffinate contained $\mathrm{Cu}\left(0.0002 \mathrm{~g} \mathrm{~L}^{-1}\right), \mathrm{Ni}\left(0.140 \mathrm{~g} \mathrm{~L}^{-1}\right)$ and $\mathrm{Zn}$ $\left(0.161 \mathrm{~g} \mathrm{~L}^{-1}\right)$. Then a two-stage counter current simulation for the stripping of $\mathrm{Cu}$ from loaded organic $\left(\mathrm{Cu}: 0.1498 \mathrm{~g} \mathrm{~L}^{-1}\right)$ with $50 \mathrm{~g} \mathrm{~L}^{-1} \mathrm{H}_{2} \mathrm{SO}_{4}$ in two stages at A:O ratio of 1:1.75 gave a stripping efficiency of $99.8 \%$ copper. Ni extraction for $\mathrm{Cu}$ raffinate was carried at an equilibrium $\mathrm{pH}$ of 7.50, which gave a $\mathrm{Ni}$ extraction efficiency of $92 \%$ at an $\mathrm{A}: \mathrm{O}$ ratio of 1:1.2. A twostage counter current simulation for the extraction of $\mathrm{Ni}$ at $\mathrm{A}: \mathrm{O}$ of 1:1.2 was conducted. This resulted in Ni raffinate containing $0.001 \mathrm{~g} \mathrm{~L}^{-1}$ of $\mathrm{Ni}$ and $0.161 \mathrm{mg} \mathrm{L}^{-1}$ of $\mathrm{Zn}$, corresponding to $\mathrm{Ni}$ extraction efficiency of $99.3 \%$. The Ni from L.O. (Ni: $0.1159 \mathrm{~g}$ $\mathrm{L}^{-1}$ ) was stripped with $50 \mathrm{~g} \mathrm{~L}^{-1} \mathrm{H}_{2} \mathrm{SO}_{4}$ in two stages at an $\mathrm{A}: \mathrm{O}$ ratio of $1: 1.5$, which gave a stripping efficiency of $98.9 \%$. The resultant $\mathrm{Ni}$ raffinate was further processed for $\mathrm{Zn}$ extraction at an equilibrium $\mathrm{pH}$ of 9.0. Single-stage extraction data with the same extractant indicated extraction efficiency of $99.5 \%$ at A:O ratio of unity. Zinc from L.O. (Zn: $0.1602 \mathrm{~g} \mathrm{~L}^{-1}$ ) was then subjected to stripping with $150 \mathrm{~g} \mathrm{~L}^{-1} \mathrm{H}_{2} \mathrm{SO}_{4}$ in two stages at an A:O ratio of 1:1, which gave a stripping efficiency of $99 \%$.

\section{Conclusions}

LIX 84I, a commercial extractant supplied by Cognis, Ireland, was exploited for solvent-extraction studies of $\mathrm{Ni}$ (II) from a sulfate medium and the recovery of $\mathrm{Cu}(\mathrm{II}), \mathrm{Ni}(\mathrm{II})$ and $\mathrm{Zn}$ (II) from a synthetic solution. The extraction of $\mathrm{Ni}(\mathrm{II})$ depends on the equilibrium $\mathrm{pH}$ of the aqueous phase and the extractant concentration, and follows a cation-exchange mechanism. Based on the differences in the extraction behavior of various metals, this extractant clearly indicated the possible separation of $\mathrm{Cu}(\mathrm{II}), \mathrm{Ni}(\mathrm{II})$ and $\mathrm{Zn}(\mathrm{II})$. Complete flow sheet of the process was developed, and the obtained metals were in pure form.

\section{Acknowledgements}

The authors express sincere thanks to Ministry of Environment \& Forests (MOEF), Government of India, New Delhi, India for financial support. Thanks are also to Dr. J. S. Yadav, Director and Dr. B. M. Choudary, Head, Inorganic and Physical Chemistry Division IICT, Hyderabad for their constant encouragement and permission to publish this work. Thanks are also due to Cognis, USA, for providing a LIX 84I sample.

\section{References}

1. D. S. Flett and D. W. West, "Complex Metallurgy 78", Paper International Symposium, ed. M. J. Jones, 1978, Inst. Min. Metall., London, England, 49 - 57.

2. J. S. Preston, Hydrometallurgy, 1982, 9, 115.

3. W. A. Rickelton, D. S. Flett, and D. W. West, Solvent. Extr. Ion Exch., 1984, 2, 815.

4. A. W. Ashbrook and G. M. Ritcey, paper presented at the Conference of Metallurgists, 1971, Montreal, Canada, August 30, 45.

5. B. R. Reddy and P. V. R. Bhaskara Sarma, Miner. Metall. Process., 2001, 18, 172.

6. P. V. R. Bhaskara Sarma and B. R. Reddy, Miner. Eng., 2002, 15, 461 .

7. C. Parija, B. R. Reddy, and P. V. R. Bhaskara Sarma, Hydrometallurgy, 1998, 49, 255.

8. G. A. Kordosky, S. M. Olafson, R. G. Lewis, V. L. Deffner, and J. E. House, Sep. Sci. Technol., 1987, 22, 215.

9. A. I. Ali, J. A. Daoud, and H. F. Aly, J. Chem. Technol. Biotechnol., 1996, 67, 137.

10. J. Yang, "Proceedings of International Solvent Extraction Conference, ISEC'1993", ed. D. H. Logsdail and M. J. Slater, 1993, Vol. 1, York, UK, $183-188$.

11. J. H. Russell and R. L. Rickel, Solvent. Extr. Ion Exch., 1990, 8,855 .

12. F. Hu, "Proceedings of International Solvent Extraction Conference, ISEC'1996", ed. D. C. Shallcross, R. Paimin, and L. M. Prvcic, 1996, Vol. 1, Melbourne, Australia, 727 732.

13. M. J. Price and J. G. Reid, "Proceedings of International Solvent Extraction Conference, ISEC'93", ed. D. H. Logsdail and M. J. Slater, 1993, Vol. 1, York, UK, 159 166.

14. A. I. Vogel, "A Text Book of Quantitative Analysis Including Elementary Instrumental Analysis", 3rd ed., 1961, ELBS and Longmans, Green and Co Ltd., 435. 